\title{
Buku Seni (Artist’s Book) Sebagai Media Diplomasi Budaya Indonesia-Jerman
}

\author{
Agus Dody Purnomo', Toni Masdiono ${ }^{2}$ \\ ${ }^{1}$ Universitas Telkom, Jl. Telekomunikasi, Terusan Buah Batu Bandung, 40257, Indonesia \\ ${ }^{2}$ Sekolah Tinggi Desain Indonesia, Jl. Wastukencana 52 Bandung, 40116, Indonesia \\ Iadpenggar@gmail.com
}

\begin{abstract}
Seni merupakan alat yang ampuh sebagai sarana diplomasi damai (soft diplomacy) dalam pergaulan dunia saat ini. Melalui seni jati diri suatu bangsa dapat dikenal oleh masyarakat dunia. Seni juga dapat menjadi penyeimbang dalam kehidupan yang serba seragam di era global. Buku seni (artist's book) sebagai salah satu bentuk karya seni rupa dapat menjadi sarana diplomasi budaya dengan negara Jerman. Buku seni merupakan media ungkap ekspresi dari seniman sehingga buku seni memiliki bentuk dan tampilan yang unik. Buku seni juga berbeda dengan buku-buku pada umumnya dimana di dalamnya berisi teks dan ilustrasi. Buku seni juga dicetak dalam edisi terbatas sehingga semakin memberikan kesan ekslusif. Folklor lisan yang berkembang di tanah Sunda menjadi sumber ide untuk isi buku seni. Sedangkan medium buku seni menggunakan kertas Daluang salah satu kertas tradisional yang berkembang di tanah air. Dari aspek isi dan medium kertas yang digunakan mencerminkan kekayaan budaya yang ada di Nusantara. Perlu dipahami bahwa di era global keunikan dan keragaman budaya Nusantara dapat dipakai untuk bersaing dengan bangsa lain. Melalui kegiatan workshop dan pameran buku seni di Berlin, Jerman menjadi salah satu cara memperkenalkan budaya Nusantara ke luar negeri.
\end{abstract}

Kata kunci : buku seni, kertas daluang, diplomasi budaya

\section{Artist's Book as a Cultural Diplomacy Between Indonesian and Germany}

Art is a powerful tool as a means of peaceful diplomacy (soft diplomacy) in today's world relations. Through the art of identity a nation can be known by the world community. Art can also be a counterweight in life that is completely uniform in the global era. Artist's book as a form of art can be a means of cultural diplomacy with the Germany. Artist's book is a medium of expression of the artist's so that it has a unique and appearance. Artist's book is also different from books in general, which contains text and illustrations. Artist's book is also printed in limited editions so that it give an exclusive. Oral folklore that developed in Sundanese became a source of ideas for the contents of artist's book. While the artist's book medium uses Daluang paper one of the traditional paper in the country. From the aspect of content and the medium of paper used, reflect the cultural richness that existsin the archipelago. In the global era the uniqueness and cultural diversity of the archipelago can be used to compete with other nations. Through workshops and artist's book exhibitions in Berlin, Germany it has become a way to inroduce the cultura of the archipelago to foreign countries.

Keywords : artist's book, daluang paper, culture diplomacy

Proses Review : 1 - 28 Januari 2020, Dinyatakan Lolos: 10 Februari 2020 


\section{PENDAHULUAN}

Globalisasi membawa dunia ini seakan-akan menjadi satu (homogenisasi global). Hal ini didukung dengan kemajuan teknologi komunikasi dan informasi yang menyebabkan terjadinya percepatan penyebaran informasi termasuk di dalamnya penyebaran identitas lokal maupun nasional ke ranah global. Melalui teknologi internet setiap orang dapat terhubung satu dengan yang lain sehingga memungkinkan mereka melakukan kontak nilai dan budaya yang berbeda termasuk di dalamnya yaitu melalui seni.

Seni merupakan alat yang ampuh sebagai sarana diplomasi damai dalam pergaulan dunia saat ini. Melalui seni, jati diri suatu bangsa dapat dikenal oleh masyarakat dunia. Bahkan seni dapat menjadi penyeimbang dalam kehidupan yang nyaris serba seragam di era global sekarang. Hal tersebut merupakan bentuk kontribusi nyata dari seni bagi kemajuan suatu bangsa. Istilah 'diplomasi' berdasarkan Kamus Bahasa Indonesia yakni kecakapan menggunakan pilihan kata yang tepat dalam perundingan, atau arti lainnya urusan hubungan antara suatu negara dengan negara lain secara resmi (Hizair, 2013). Sedangkan Tulus Warsito dan Wahyuni Kartikasari, mengemukakan bahwa diplomasi kebudayaan sebagai upaya suatu negara untuk memperjuangkan kepentingan nasionalnya melalui dimensi kebudayaan, baik secara mikro seperti pendidikan, ilmu pengetahuan, olahraga, dan kesenian, ataupun secara makro sesuai dengan ciri-ciri khas yang utama, misalnya propaganda dan lain-lain, yang dalam pengertian konvensional dapat dianggap sebagai bukan politik, ekonomi, ataupun militer (Sinulingga, 2017). Seni sebagai sarana diplomasi antar bangsa termasuk dalam kelompok Soft Diplomacy. Melalui seni keberadaan suatu bangsa dapat dikenal. Bahkan oleh beberapa negara maju dimanfaatkan untuk mempengaruhi negara-negara berkembang.

Salah satu bentuk seni rupa yang keberadaannya di Indonesia mungkin tidak sepopuler seni lukis dan seni patung yakni buku seni (artist's book). Buku seni lebih dekat berkaitan dengan seni grafis. Hal ini dikarenakan proses pengerjaannya melalui proses cetak (printmaking). Selain itu kemunculan buku seni juga turut mewarnai sejarah perkembangan seni grafis Eropa khususnya di negara Jerman tempat ditemukannya mesin cetak Gutenberg sekaligus pelopor pembuatan buku seni. Walaupun buku seni di Indonesia tidak sepopuler seni lukis maupun seni patung, namun buku seni pernah dipakai sebagai sarana diplomasi budaya dengan negara lain.

Dalam sejarah perkembangan seni grafis di Indonesia, seniman Baharuddin Marasutan (1911-1988) dan Mochtar Apin (1923-1994) pernah bekerjasama menerbitkan buku seni untuk merayakan ulang tahun pertama Republik Indonesia pada tahun 1946. Buku seni tersebut hanya dicetak 36 eksemplar yang berisi 19 karya seni dan dikirimkan ke negara-negara yang telah mengakui kemerdekaan Indo- nesia (Soemantri, 2002 : 90). Berisi karya grafis yang bertemakan potret kehidupan rakyat Indonesia. Ilustrasinya dikerjakan dengan teknik Linolium sedangkan teksnya dengan tipografi sederhana yang diterjemahkan dalam bahasa Inggris dan Perancis (Adisasmita, 2002 : 9).

Istilah 'buku seni' berasal dari bahasa Perancis Livre de Paintre, sedangkan dalam bahasa Inggris disebut 'Bibliophile' atau 'Artist's Book'. Dalam bahasa Jerman dikenal dengan istilah 'Koenstlerbuch' atau 'Mal erbuch'. Kata 'Koenstler' artinya adalah seniman, sedangkan Maier artinya adalah pelukis dan Buch artinya buku. Dari istilah tersebut dapat diartikan sebagai buku seniman, karena buku sebagai media ungkap ekspresi dari seniman (Adisasmita, 2002). Sedangkan di Indonesia istilah tersebut lebih dikenal sebagai 'buku seni' (artist's book).

Buku seni umumnya hasil karya kolaborasi antara seniman perupa dengan sastrawan. Selain itu juga layaknya media ungkap bagi seniman, dimana di dalamnya terdapat unsur-unsur estetik. Buku tersebut berisi tulisan dan ilustrasi/ gambar yang menjadi kesatuan utuh. Jadi buku seni berbeda dengan buku-buku pada umumnya karena dirancang oleh seniman dimana secara proses pembuatan mengandung unsur-unsur keindahan. Mulai dari isi, bentuk, layout / tata letak, bentuk huruf, ilustrasi, pemilihan material, kulit muka hingga penjilidan, menjadi kesatuan unsur perupaan yang utuh. Selain dari segi tampilan dan isi yang berbeda dengan buku pada umumnya, jumlah edisi cetakan juga dibatasi. Didukung dengan ilustrasi/gambar yang dibuat dengan teknik seni grafis semakin memberikan kesan ekslusif. Bagi beberapa orang jika dapat memiliki buku seni menjadi suatu kebanggaan dimana isinya tidak hanya untuk dibaca namun juga dapat dinikmati karena keindahan gambarnya yang ada di dalamnya. Selain karena teks dan gambar, seorang penikmat buku seni seolah-olah juga dapat merasakan dan menghayati seniman pembuatnya melalui karakter kertas serta cetakan hurufnya.

Di negara asalnya yakni Jerman, awalnya buku seni dipakai dalam penulisan manuscrip keagamaan. Kemudian oleh para misionaris dimanfaatkan untuk penyebaran ajaran Nasrani di Eropa. Buku seni semakin berkembang setelah ditemukannya mesin cetak Gutenberg pada sekitar abad XV. Sedangkan untuk pembuatan ilustrasinya dibuat dengan teknik seni grafis (printmaking), antaralain: teknik cetak tinggi/cukil kayu, teknik cetak dalam (intaglio), dan cetak datar (lithografi).

Beberapa seniman dunia yang pernah berkarya melalui buku seni antaralain: Monet, Pablo Picasso, Georges Braque, Joan Miro, Marc Chagall, Henry Matisse. Bukubuku karya Picasso, Miro, dan Chagall dianggap sebagai tonggak sejarah penciptaan buku seni modern di Eropa (Adisasmita, 2002). Sedangkan di Indonesia, buku seni diperkenalkan oleh seniman grafis yaitu Mochtar Apin dan karya yang dibuat berjudul "Pantjangan Pertama" yang 
dibuat dengan teknik Linolium. Dalam perkembangannya seniman lainnya yang ikut andil, antaralain: Iskandar, But Muchtar, Saini, AD Pious, Srihadi, Sidharta, Kaboel Suadi, Jusuf Affendy, Priyanto. S, Haryadi Suadi, dan Angkama Setjadipradja. Hingga tahun 70 -an para seniman di tanah air aktif dalam memproduksi buku seni.

Umumnya buku seni dicetak di atas kertas cotton (kertas yang umum dipakai dalam seni grafis). Namun kali ini buku seni memakai kertas Daluang (kertas tradisional Sunda). Hal ini untuk mendukung tujuan utama yakni memperkenalkan potensi budaya lokal ke internasional. Begitupula untuk materi isi dalam buku seni juga mengangkat folklor lisan Nusantara.

Folklor adalah sebagian kebudayaan suatu kolektif, yang tersebar dan diwariskan secara turun-temurun, diantara kolektif macam apa saja, secara tradisional dalam versi yang berbeda, baik dalam bentuk lisan maupun contoh yang disertai dengan gerak isyarat atau alat pembantu pengingat (mnemonic device) (Danandjaya, 1991:1-2). Sedangkan foklor menurut Kamus Bahasa Indonesia merupakan cerita rakyat yang turun-temurun dan tidak dibukukan (Hizair, 2013 : 188). Jika ditinjau dari cara penyebarannya, folklor pada umumnya melalui tutur kata atau lisan, sehingga ada yang menyebutnya sebagai tradisi lisan (oral tradition). Menurut Prof. Setya Yuwana Sudikan, tradisi lisan adalah berbagai pengetahuan dan adat kebiasaan yang secara turun-menurun disampaikan secara lisan dan mencakup hal-hal tidak hanya berisi cerita rakyat, mite, dan legenda tetapi menyimpan sistem kognasi (kekerabatan) asli yang lengkap, sebagai contoh sejarah, praktik hukum, hukum adat, pengobatan (Endraswara, 2013). Dan umumnya tradisi lisan tersebut sarat dengan ajaran maupun nasehat yang sesuai dengan budaya setempat. Untuk itu dalam proyek penciptaan buku seni ini mengangkat folklor lisan yang berkembang di Tatar Sunda. Hal ini dilakukan mengingat bahwa di era global keunikan dan keragaman budaya Nusantara merupakan alat ampuh yang dapat dipakai dalam bersaing dengan bangsa lain.

\section{METODE PENELITIAN}

Metode melalui penciptaan karya yakni berupa kegiatan workshop. Kegiatan workshop dilaksanakan di Druckwerkstatt Kulturwerk BBk Berlin, Jerman. Sedangkan untuk pembuatan kertas Daluang melibatkan seorang pengrajin kertas Daluang yang masih bertahan di Dago Pojok, Bandung, Indonesia.

Kegiatan awal di Indonesia (Bandung) mempersiapkan materi folklor lisan (cerita rakyat) Sunda yang akan dibuat dalam buku seni. Cerita yang dipilih antara lain: Sangkuriang, Ciung Wanara, Telaga Warna, dan Mundinglaya Dikusumah. Selain itu juga memesan medium yang akan dipakai untuk buku seni yakni kertas Daluang. Mengingat proses pembuatan kertasnya membutuhkan waktu yang cukup karena produksinya dilakukan secara tradisional serta bergantung pada kondisi cuaca khususnya sinar matahari.

Kegiatan workshop buku seni bertempat di studio Druckwerkstatt Kulturwerk BBk Berlin, Jerman meliputi: pembuatan sketsa dan plat cetak serta proses cetak. Pembuatan sketsa yakni pembuatan ilustrasi buku seni berupa gambar sketsa di atas papan linocut. Gambar sketsa yang sudah jadi dibuat sebagai bahan acuan cetak (plat), teknik pengerjaan dengan cara teknik cukil. Sedangkan pembuatan teks dilakukan dengan pembuatan teknik Nylo-print, acuan cetak khusus lewat proses foto-mekanik. Teks dibuat dalam dua bahasa yakni bahasa Indonesia dan bahasa Jerman. Penulisan teks dalam bahasa Jerman dibantu oleh Prof. DR. Peter Sternagel (profesor Hochschule fur Bildende Kunste di Braunschweig).

Proses cetak untuk ilustrasi dan teks menggunakan mesin cetak yang disediakan pihak Druckwerkstatt Kulturwerk BBk Berlin. Buku seni dicetak dengan memakai bahan kertas Daluang. Selama ini medium pembuatan buku seni memakai kertas cotton ex Jerman. Namun kali ini mencoba memakai medium yang lain yakni kertas tradisional Daluang. Hal ini dilakukan sebagai bahan alternatif sekaligus juga sarana memperkenalkan kertas tradisional Sunda ke masyarakat internasional.

Kegiatan terakhir dengan mengadakan pameran karya hasil workshop. Pameran berlangsung selama dua minggu dan bertempat di ruang galeri Druckwerkstatt Kulturwerk BBk Berlin, Jerman. Pembukaan pameran diresmikan oleh Atase Pendidikan Kedubes Republik Indonesia - Berlin dan dihadiri beberapa staf Kedubes RI Berlin serta masyarakat Indonesia yang berada di Berlin.

\section{PROSES PERWUJUDANNYA}

\section{Kertas Daluang Medium Buku Seni}

Di bawah ini akan diuraikan terlebih dahulu tahapan dalam pembuatan kertas Daluang. Pembuatan kertas Daluang dilaksanakan di daerah Dago Pojok Bandung, Indonesia oleh seorang pengrajin kertas yang masih bertahan. Kertas Daluang di Nusantara memiliki istilah yang berbeda-beda, antaralain : Daluang (Jawa Barat), Dluwang (Jawa Tengah), kertas Gendong/Gedhok (Jawa Timur), Dhalubang (Madura), dan istilah lainnya di tanah air. Istilah Daluang sendiri dalam Kamus Bahasa Indonesia yakni jenis kain atau kertas yang dibuat dari kulit pohon (Hizair, 2013 : 141). Memang sejak jaman dulu masyarakat sering memanfaatkan kertas Daluang untuk bahan pakaian dan media dalam penulisan naskah-naskah kuno.

Kertas Daluang terbuat dari bahan kulit batang pohon Saeh (Broussonetia papyryfera Vent) yakni sejenis tumbuhan tingkat rendah termasuk dalam keluarga Moraceae. Di beberapa tempat disebut pula Paper moerbeiboom, Murier 


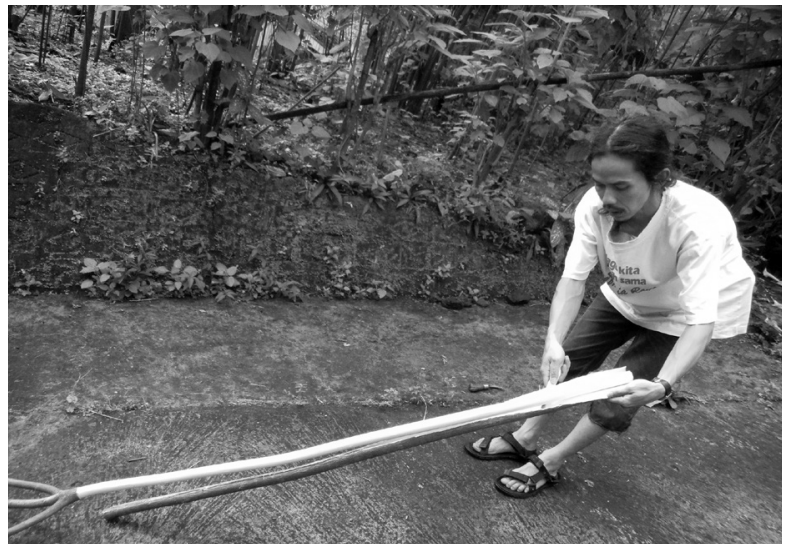

Gambar 1. Kulit batang pohon Saeh (Broussonetia papyryfera Vent) bahan kertas Daluang. (Sumber: dokumentasi penulis)

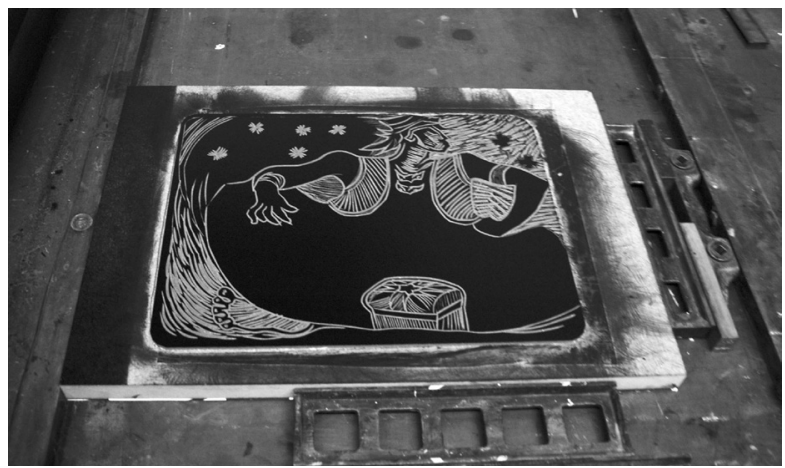

Gambar 3. Plat cetak yang dibuat di atas papan lino untuk ilustrasi buku seni. (Sumber: dokumentasi penulis)

a papier, Japanischer papierbaum atau paper mulberry. Dalam istilah lain tanaman ini disebut sepukau di Basemah, glugu / galugu (Jawa), dhalubang / dhulubang (Madura), kembala / rowa (Sumba Timur dan Barat), linggowas (Banggai), iwo (tembuku), dan malak di Alf Seram (Tedi Permadi, 2007).

Umur pohon Saeh (Broussonetia papyryfera Vent) yang sudah 1(satu) tahun adalah usia ideal untuk dipanen, dimana tinggi pohon sekitar 6 meter dengan diameter batang $20 \mathrm{~cm}$. Batang yang sudah dipotong kemudian dikelupas kulitnya. Kulit tersebut dilepaskan dari kulit luarnya (berwarna coklat), yang akan dipakai untuk bahan kertas adalah kulit dalamnya (berwarna putih). Setelah itu direndam air semalaman untuk melunakan kulit kayu. Berikutnya dijemur di bawah sinar matahari agar cairannya (lendir) keluar.

Kulit kayu yang telah kering kemudian dilakukan proses pemukulan dengan memakai alat pemukul khusus. Alat tersebut pada bagian kepala terbuat dari bahan kuningan dan bertekstur. Tekstur pada permukaan alat pemukul umumnya dibuat tekstur bergaris, ada yang tebal ada juga tipis. Hal ini akan mempengaruhi tampilan permukaan tekstur kertas Daluang. Proses ini selain menghasilkan tekstur kertas juga dapat dipakai untuk menentukan ketebalan kertas yang diinginkan. Setelah itu kertas kembali dijemur.

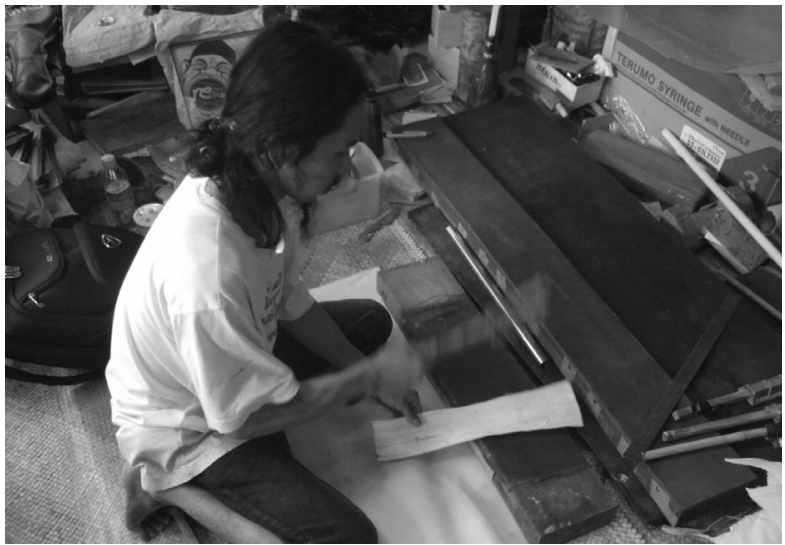

Gambar 2. Proses pembuatan kertas Daluang masih dilakukan secara tradisional. (Sumber: dokumentasi penulis)

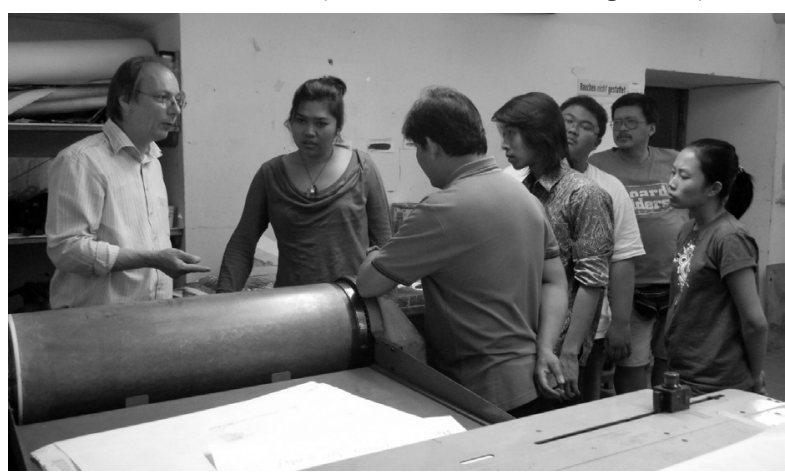

Gambar 4. Mathias Mrowka saat memberikan pengarahan penggunaan mesin cetak. (Sumber: dokumentasi penulis)

Proses penjemuran bergantung pada sinar matahari dan kondisi cuaca.

Tahap akhir adalah proses pemotongan sesuai dengan ukuran kertas yang diinginkan. Sebelum dipotong, kertas terlebih dahulu dihaluskan permukaannya menggunakan alat khusus yang mempunyai permukaan licin namun keras, seperti: cangkang kerang laut (Cypraea tigris tigris). Semua tahapan proses pembuatan masih dilakukan secara manual. Hal ini yang menyebabkan kertas Daluang memiliki keunikan dan ekslusif.

\section{Folklor Lisan Dalam Buku Seni}

Dan berikutnya akan diuraikan proses pembuatan buku seni. Tahap awal menentukan materi isi buku seni yang mengambil ide dari folklor lisan yang ada di tanah Sunda. Dipilih empat folklor kemudian masing-masing folklor akan dibuat 3 (tiga) ilustrasi dan 3 (tiga) narasi / teksnya. Persiapan materi ini dilaksanakan di Bandung, Indonesia. Sedangkan kegiatan workshop pembuatan buku seni dilaksanakan di Druckwerkstatt Kulturwerk BBK Berlin, Jerman. Dimulai dengan pembuatan sketsa awal di atas kertas, jika sudah sesuai kemudian digambar ulang pada permukaan papan lino (bahan papan ini hanya tersedia di Jerman). Tahap berikutnya adalah tahap pencukilan menggunakan pisau pahat/cukil. Gambar sketsa yang sudah jadi dibuat untuk bahan acuan cetak (plat), teknik pengerjaan 


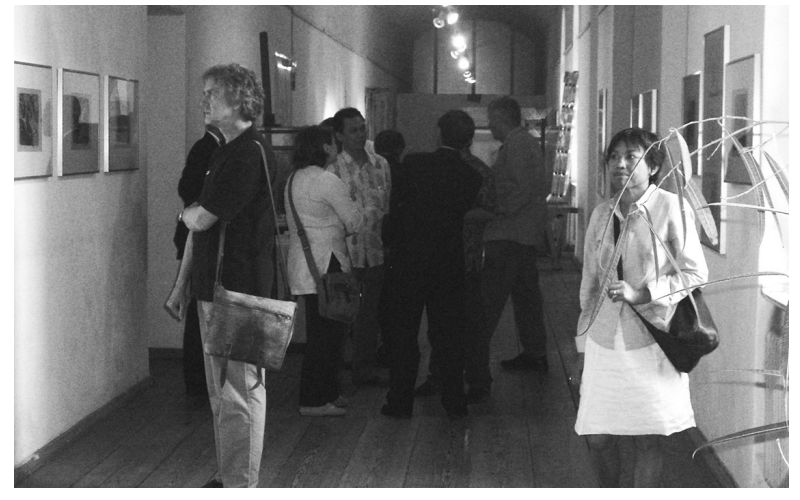

Gambar 5. Kegiatan pameran buku seni berlangsung di galeri Druckwerkstatt Kulturwerk BBk Berlin, Jerman.

(Sumber: dokumentasi penulis)

plat dengan cara teknik cukil. Pencukilan adalah tahap terpenting dalam pembuatan karya tersebut karena kualitas karya ditentukan pada tahap ini. Sementara pembuatan teks dilakukan dengan pembuatan teknik Nylo-print, acuan cetak khusus lewat proses foto-mekanik. Teks dibuat dalam dua bahasa yaitu bahasa Indonesia dan bahasa Jerman. Perlu diingat bahwa plat cetak baik untuk gambar dan teks dibuat secara terbalik.

Proses cetak baik untuk ilustrasi dan teks narasinya mengunakan mesin cetak yang sudah disediakan oleh pihak setempat. Sebelum melaksanakan proses cetak, peserta workshop diberi pengarahan oleh direktur Druckwerkstatt Kulturwerk BBK Berlin yakni Mathias Mrowka tentang teknik penggunaan mesin cetak tersebut. Buku seni dicetak dengan memakai bahan kertas Daluang sebagai medium sekaligus akan diperkenalkan ke masyarakat Jerman melalui kegiatan pameran.

Kegiatan terakhir yakni pameran buku seni yang dihasilkan selama workshop di Jerman. Pameran berlangsung selama dua minggu di galeri Druckwerkstatt Kulturwerk $B B k$ Berlin, Jerman dan dibuka oleh Atase Pendidikan Kedubes RI - Berlin. Pembukaan pameran dihadiri oleh masyarakat Jerman serta warga Indonesia yang tinggal di Jerman.

\section{WUJUD KARYA}

Buku seni yang diproduksi selama workshop di Jerman berjumlah 6 (enam) edisi. Masing-masing edisi terdiri dari 26 lembar halaman. Urutan isi setiap lembarnya yakni diawali halaman cover depan (berupa ilustrasi dan teks judul buku). Dilanjutkan halaman pertama yang memuat judul, daftar nama orang yang terlibat dalam pembuatan buku seni, dan nama lembaga serta tahun produksi. Kemudian dilanjutkan dengan halaman narasi berupa teks kisah setiap folklor dan dilengkapi lembar halaman untuk ilustrasinya. Masing-masing kisah terdiri dari 3 (tiga) lembar narasi dan 3 (tiga) lembar ilustrasi. Jadi jumlah lembar untuk narasi dan ilustrasi semuanya ada 24 lembar.
Satu edisi disajikan dalam bentuk karya yang dibingkai untuk materi pameran di Jerman. Dan selanjutnya setelah kegiatan pameran, edisi tersebut menjadi dokumentasi pihak Druckwerkstatt Kulturwerk BBK Berlin. Sedangkan lima edisi lainnya disajikan dengan kemasan khusus yakni satu bendel dimasukan dalam boks khusus sehingga menambah kesan ekslusif. Satu boks diberikan untuk pihak Kedubes RI - Berlin. Satu boks berikutnya dikirim ke Kedutaan Besar Indonesia untuk Unesco yang berkantor di Paris, Perancis. Dua boks lagi untuk diserahkan kepada Direktorat Jenderal Pendidikan Tinggi (Dikti) di Jakarta selaku penyandang dana kegiatan Muhibah Seni ini. Dan sisanya untuk dokumentasi tim peserta workshop.

Berikut contoh narasi dan ilustrasi pada salah satu kisah yang diangkat dalam buku seni yakni Sangkuriang:

\section{Lembar (1)}

Narasi dalam bahasa Indonesia:

Alkisah, hiduplah Sangkuriang seorang anak lelaki dari seorang putri raja berparas jelita, Dayang Sumbi.

Sangkuriang diusir oleh Dayang Sumbi karena telah membunuh anjing kesayangannya, Tumang.

Narasi dalam bahasa Jerman:

Sangkuriang war der Sohn einer wunderschönen Königstochter, Dayang Sumbi.

Sangkuriang wurde von Dayang Sumbi vertrieben, weil er ihren Lieblingshund Tumang getötete hatte.

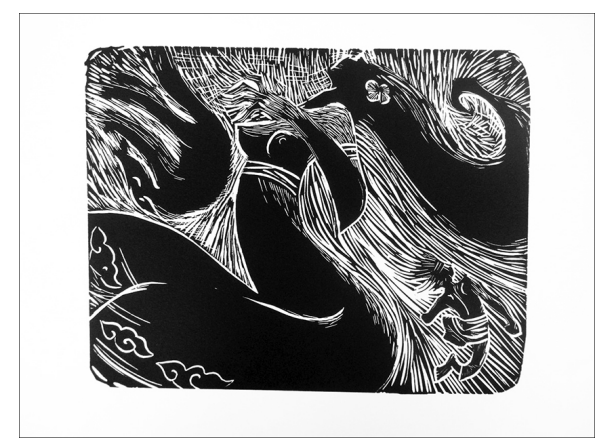

Gambar 5. Dayang Sumbi saat mengusir Sangkuriang karena telah membunuh si Tumang. Sumber: dokumentasi penulis.

\section{Lembar (2)}

Narasi dalam bahasa Indonesia:

Dayang Sumbi tak menyangka sosok jejaka tampan yang merebut hatinya ialah darah dagingnya.

Sangkuriang dapat mempersunting Dayang Sumbi jikalau dapat membuat sebuah perahu kokoh nan megah.

\section{Narasi dalam bahasa Jerman:}

Dayang Sumbi ahnte nicht, dass in den Adern des schönen Jünglings, der ihr Herz erobert hatte, Blut von ihrem Blut floss.

Sangkuriang würde Dayang Sumbi zur Frau bekommen, wenn er ein großes, starkes Boot baute. 


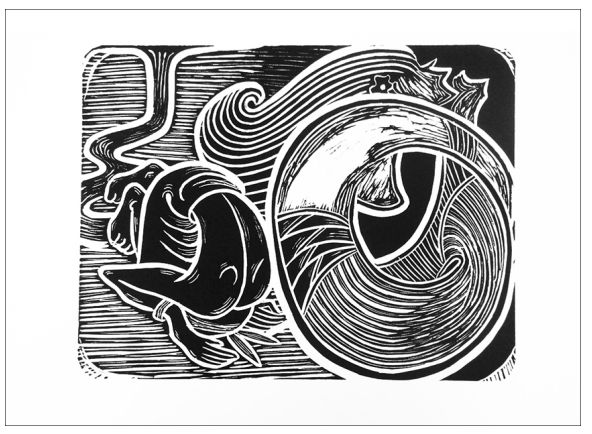

Gambar 6. Dayang Sumbi tak menyangka lelaki tampan itu adalah Sangkuriang. (Sumber: dokumentasi penulis)

\section{Lembar (3)}

Narasi dalam bahasa Indonesia:

Sangkuriang tak mampu berlapang dada atas kegagalannya memenuhi syarat suntingan, segenap angkara murkanya diluapkan pada perahu yang dibuatnya hingga menelungkup, yang sejak saat itu disebut Gunung Tangkuban Perahu.

Narasi dalam bahasa Jerman:

Sangkuriang ertrug es nicht, dass er die Bedingung für die Hochzeit nicht erfüllen konnte, und stieß voller Zorn das fast fertige Boot um, seitdem heißt es Gunung Tangkuban Perahu, das bedeutet das Boot Tangkuban.

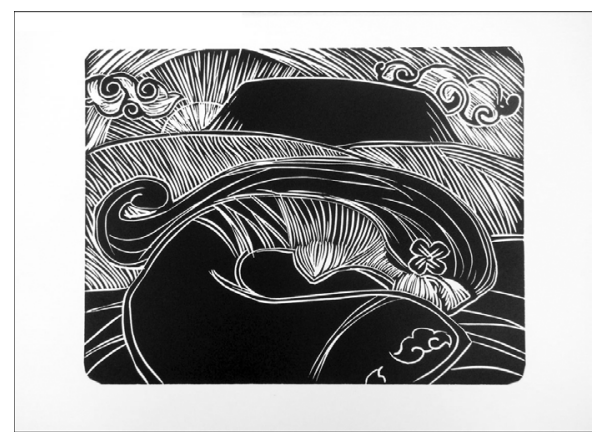

Gambar 7. Perahu yang menelungkup akhirnya menjadi Gunung Tangkuban Perahu (Sumber: dokumentasi penulis)

\section{SIMPULAN}

Buku seni dapat menjadi sarana untuk melakukan diplomasi budaya (soft diplomacy) sekaligus untuk memperkenalkan budaya Nusantara ke dunia internasional khususnya negara Jerman sebagai negara pelopor buku seni. Keunikan dan keindahan tampilan buku seni memberi kesan ekslusif sehingga layak untuk ditampilkan di kancah internasional.

Folklor lisan yang berkembang di Nusantara dapat menjadi sumber ide untuk disajikan dalam medium visual seperti buku seni ini. Kisah cerita yang menarik dan sarat dengan ajaran yang sesuai dengan budaya Timur menunjukkan jati diri suatu bangsa sekaligus menjadi pembeda di era global saat ini.
Di tengah perkembangan teknologi informasi dan komunikasi yang semakin cepat khususnya teknologi internet justru menjadi peluang dalam penyebaran informasi tentang keunikan budaya Nusantara. Untuk itu pengembangan buku seni dapat dihadirkan dalam tiga bentuk. Bentuk pertama dengan dicetak dan diproduksi dalam edisi terbatas karena memang dikhususkan bagi penikmat seni. Sedangkan bentuk yang kedua direproduksi dalam format digital dengan memanfaatkan media online sehingga dapat diakses oleh generasi milenial. Dan bentuk yang terakhir dicetak dalam format buku bacaan sehingga dapat dinikmati bagi masyarakat yang tetap memilih buku sebagai hiburannya.

\section{DAFTAR RUJUKAN}

Adisasmita, Nuning Damayanti. (2002), Buku Seniman - Buku Sebagai Objek Berekspresi dalam Berkesenian, Mengapa Tidak?, Jurnal Wacana Seni Rupa, vol. 2 No. 4, STISI TELKOM, Bandung.

Danandjaya, James. (1991), Folklor Indonesia - Ilmu gosip, dongeng, dan lain-lain, Pustaka Utama Grafiti, Jakarta.

Endraswara, Suwardi. (2013), Folklor Nusantara - Hakikat, Bentuk, dan Fungsi, Penerbit Ombak, Yogyakarta.

Marianto, M. Dwi. (1988), Seni Cetak Cukil Kayu, Penerbit Kanisius, Yogyakarta.

MA, Hizair. (2013), Kamus Lengkap Bahasa Indonesia, TAMER, Jakarta.

Permadi, Tedi,__, Asal-Usul Pemanfaatan dan Karakteristik Daluang: Bahan Naskah dalam Tradisi Tulis Nusantara, Bandung: FPBS UPI, makalah diunduh pada tanggal 15 Maret 2019.

Sinulingga, Sarah Patrecia. (2017), Diplomasi Kebudayaan Indonesia Terhadap Amerika Serikat Melalui Kuliner (Gastrodiplomacy) tahun 2010-2016, artikel JOM FISIP vol. 4 no. 2- Oktober 2017, diunduh pada tanggal 1 Agustus 2019.

Soemantri, Hilda. (2002), Indonesian Heritage - Seni Rupa, Grolier Internasional, Jakarta. 